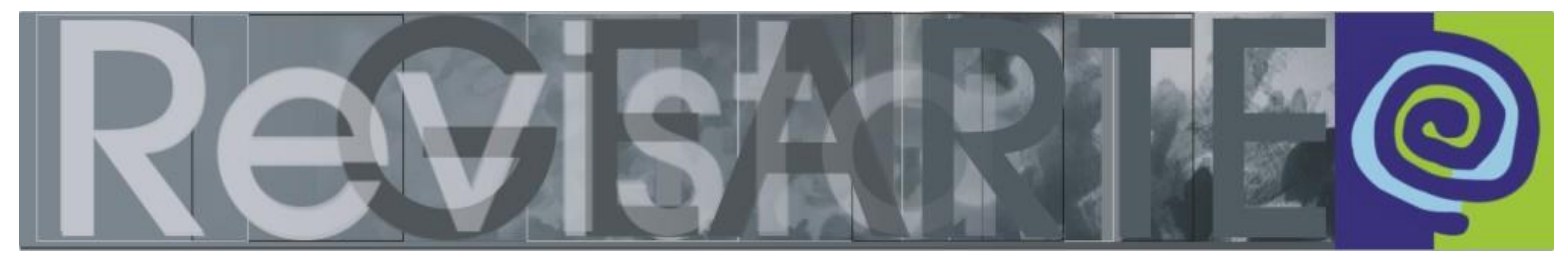

Volume 1, Número 2, Agosto/2014, ISSN 2357-9854

\title{
Arte na educação da infância: saberes e práticas da dimensão estética
}

\author{
Gilvânia Maurício Dias de Pontes (UFRN - Brasil)
}

\section{RESUMO}

O presente artigo aborda uma pesquisa que investigou a relação entre experiências estéticas e prática docente com linguagens artísticas, narradas em memoriais produzidos por professores da educação da infância. A abordagem do tema experiência estética solicitou o estabelecimento de interfaces entre aportes teóricos que envolviam diferentes campos de conhecimento, tais como filosofia, semiótica, arte/educação e pedagogia. A pesquisa teve natureza qualitativa, em que a metodologia assumiu, como princípios e estratégias de análise, a semiótica discursiva e alguns pressupostos da pesquisa (auto)biográfica, referentes à produção de narrativas como experiência de formação. $O$ corpus da pesquisa foi composto por cinco memoriais de formação. $\mathrm{Na}$ análise dos textos, buscou-se identificar como as experiências estéticas dos professores estavam presentes nos discursos que teciam sobre a sua prática.

\section{PALAVRA-CHAVE}

Experiência estética; arte/educação; formação de professores; educação da infância.

\section{RESUMEN}

Este artículo discute un estudio que investigó la relación entre las experiencias estéticas y la práctica docente con lenguajes artísticos, narrados en memoriales producidos por los profesores de la educación infantil. El acercamiento de lo tema de la experiencia estética pidió la creación de interfaces entre los enfoques teóricos que involucran diferentes campos del conocimiento, como la filosofía, la semiótica, el arte / la educación y la pedagogía. Se trata de una metodología de investigación cualitativa que asume como principios y estrategias de la análisis semiótica discursiva y algunos supuestos de la investigación (auto) biográfica, relativas a la producción de narrativas como experiencia de formación. El corpus de esta investigación se compone de cinco memoriales de la formación. En el análisis de los textos, hemos tratado de identificar cómo las experiencias estéticas de los profesores estaban presentes en los discursos que tejían sobre su práctica.

\section{PALABRAS CLAVE}

La experiencia estética; el arte/educación; la formación docente; la educación de la primera infancia.

\section{Introdução}

O trabalho aqui abordado foi, inicialmente, desenvolvido como pesquisa de Doutorado em Educação, na linha de pesquisa: Arte, Linguagem e Tecnologia do Programa de Pós-Graduação em Educação da Faculdade de Educação da Universidade Federal do Rio Grande do Sul/UFRGS. A pesquisa teve por objetivo investigar a relação entre experiências estéticas e práticas docentes com linguagens artísticas, narradas em memoriais produzidos por professores da Educação Infantil e anos iniciais do ensino fundamental, durante um curso de Especialização em Ensino de Arte e Educação Física na Infância, desenvolvido pela Universidade Federal do Rio Grande do Norte/ UFRN. O corpus da pesquisa foi composto por cinco memoriais de formação, e a eles foram anexadas cinco cartas de intenção, produzidas durante a 
seleção de ingresso no curso. Na análise dos textos, buscou-se identificar como as experiências estéticas dos professores estavam presentes nos discursos que teciam sobre sua prática.

\section{Rotas e decisões}

A pesquisa inseriu-se numa abordagem qualitativa, que requer a implicação do pesquisador, e na qual este olha o acontecimento a partir de um determinado contexto. A opção pela semiótica discursiva como uma das referências metodológicas decorre do fato de que, fundamentada especialmente pela fenomenologia, a semiótica discursiva contemporânea considera que o mundo se apresenta como uma totalidade que faz sentido. Portanto, olhar semioticamente para a escrita de professores, é considerar que esses atuam como leitores do mundo, e de suas práticas, produzindo sentidos para essas. Por outro lado, a escolha dos memoriais de formação como instrumentos de investigação nos conduziu aos princípios da pesquisa (auto)biográfica como mais um eixo de leitura e referencial metodológico.

\section{Os caminhos}

Acreditando na tese de que as experiências estéticas dos professores influenciam a elaboração de propostas e linguagens artísticas para crianças, seguimos em busca das significações que pudessem clarificar essa suposição.

A reescrita do nosso caminho de interesse pelos processos de significação da prática por professores da infância, em forma de memorial, foi o primeiro exercício de leitura dos percursos de pesquisa. Exercício complicado, e ao mesmo tempo, instigante que nos conduziu a atuar em dois lugares, o do sujeito que viveu e narrou experiências e o do leitor que busca as conexões com intencionalidade. A retomada do percurso pelo pesquisador é referida pela ASIHVIF (Associação Internacional das Histórias de Vida em Formação) como fundamental. A ASIHVIF exige dos formadores e pesquisadores que escrevam suas narrativas autobiográficas antes de acompanhar as histórias de vida de outrem (PASSEGI, 2008, p. 112).

Sair da narrativa, autorreferente, foi um segundo tipo de movimento. Essa nova experiência exigiu um caminhar de natureza diferente, e por estradas não tão conhecidas como as do exercício anterior. Como os objetivos traçados diziam respeito 
à estética e à experiência estética, os rumos tomados foram os da filosofia. Rumo(s), no plural, porque a diversidade dos discursos sobre estética e experiência estética na filosofia é grande. Estética uma questão antiga e multifacetada, que permeia a história da filosofia ocidental. Conhecer os significados para esse termo na filosofia foi um desafio necessário de contextualização do tema e de retorno ao foco do trabalho - as experiências estéticas e as práticas docentes.

Fazer escolhas se tonou imprescindível; após o passeio pela filosofia, reafirmou-se a decisão de seguir lendo aqueles que tratavam da estética como experiência do sujeito inserido no mundo. Desse modo, o estudo de alguns textos de Dewey (2010), Merleau-Ponty (1999; 2004) e Greimas (2002) sobre experiência estética acrescentaram novos desdobramentos para a abordagem sobre a experiência estética dos professores da infância.

O capítulo sobre arte/educação, que está espacialmente situado no meio da tese, foi um dos primeiros a ser escrito. A arte/educação contemporânea considera os processos de ensinar e aprender arte, também, na escola e, assim sendo, coloca professores e crianças como sujeitos que fazem escolhas e produzem sentidos para os conteúdos/linguagens da área de Arte. Além dessa relação direta com a pedagogia, os discursos sobre arte/educação e educação estética, elencados para a produção desse capítulo, nos permitiram estabelecer outras interfaces entre ensino e experiência estética. A composição dessa parte do trabalho foi fundamentada por autores como: Barbosa (1998; 2009), Pillar (1997; 2002), Rossi (2003), entre outros que abordam a formação estética em sua relação com a arte/educação.

A natureza do corpus de pesquisa - narrativas de professores - e, mais especificamente, o tipo de texto abordado - memorial de formação, exigiu uma incursão pelos processos de escrita. Quem escreve? Para que escreve? Para quem destina seu texto? Quais linguagens são articuladas para a expressão e criação do texto escrito? Foram algumas das indagações que orientaram os rumos do capítulo sobre a escrita. Como camadas, pensadas ao mesmo tempo, elas ocorriam e remetiam aos memoriais de formação nos conduzindo até a constatação de que, a escrita sobre experiências estéticas poderia em si ser também mais uma experiência estética e artística. 
A análise das cartas de intenção atendia a curiosidade de saber sobre as expectativas dos autores acerca do Curso de Especialização. As cartas foram analisadas tendo como referência a semiótica discursiva, mas especificamente, o regime da junção (LANDOWSKI, 2001). No regime de junção, a interação ocorre por meio de intercâmbio de valores entre os sujeitos. Na carta de intenção o professor, ao explicitar os valores que almeja alcançar com a participação no curso de especialização, fala sobre aprendizados e transformação de saberes e práticas.

Nos enunciados dos professores, nas cartas, a importância da relação teoriaprática é enfatizada. Os sujeitos estavam cientes de possuir um saber da experiência, desenvolvido no enfrentamento dos desafios que a atividade docente lhes colocou ao longo dos anos. Mas, essa dimensão do saber pedagógico, apesar de importante, não possibilitava ter clareza da intencionalidade das práticas docentes. Os professores pretendiam ter acesso aos discursos contemporâneos sobre saberes e práticas da área de Arte que Ihes desses elementos para ler a intencionalidade do seu fazer. Além da leitura refletida e informada, almejavam conquistar a autonomia na criação de práticas que tornassem significativos os processos de aprendizagem das crianças. Os saberes que buscavam referiam-se tanto à lógica das práticas, quanto à lógica dos discursos constituídos sobre as áreas de conhecimento e sobre as práticas docentes nessas áreas (CHARLOT, 2000).

Mas, como perceber, e analisar, a presença da dimensão estética nas narrativas escritas dos professores sobre seu processo de formação e suas propostas em linguagens artísticas para crianças?

O caminho seguido, para a abordagem da dimensão estética, foi o da análise dos memoriais, olhando pelo ângulo do regime de sentido da união (LANDOWSKI, 2005). Na união a significação é produzida no encontro entre corpos condutores de sentido. Corpos dotados de competência estésica que entram em contrato com outros objetos e sujeitos dotados de consistência estésica, isto é de qualidades sensíveis oferecidas à percepção.

As interfaces entre experiência estética, ensino e arte, também, serviram de norte para a leitura dos textos dos professores. As narrativas de experiências 
encontradas nos memoriais convergem na ênfase em alguns aspectos, mas são compostas também por particularidades que singularizam o percurso de cada autor.

No texto de Vitor (2007), os projetos de vida e formação acionam as linguagens tanto da Arte quanto da Educação Física. Vitor se constitui como professora em interação com as duas áreas. A autora enfatiza a Cultura de Movimento como campo de conhecimento que comporta as interfaces entre os saberes das referidas áreas. Tal interface é almejada por ela quando da organização de sua prática docente. A formação como atriz é articulada a sua atuação como professora e é refletida tendo como referência os pressupostos da Cultura de Movimento. Quando trata do trabalho com crianças, ela prioriza a interdisciplinaridade e o diálogo como fundamentais a sua atuação. $\mathrm{Na}$ escrita do relato reflexivo sobre a prática docente, Vitor relaciona suas experiências com a arte circense aos interesses das crianças, para transformar esse tema em projeto didático.

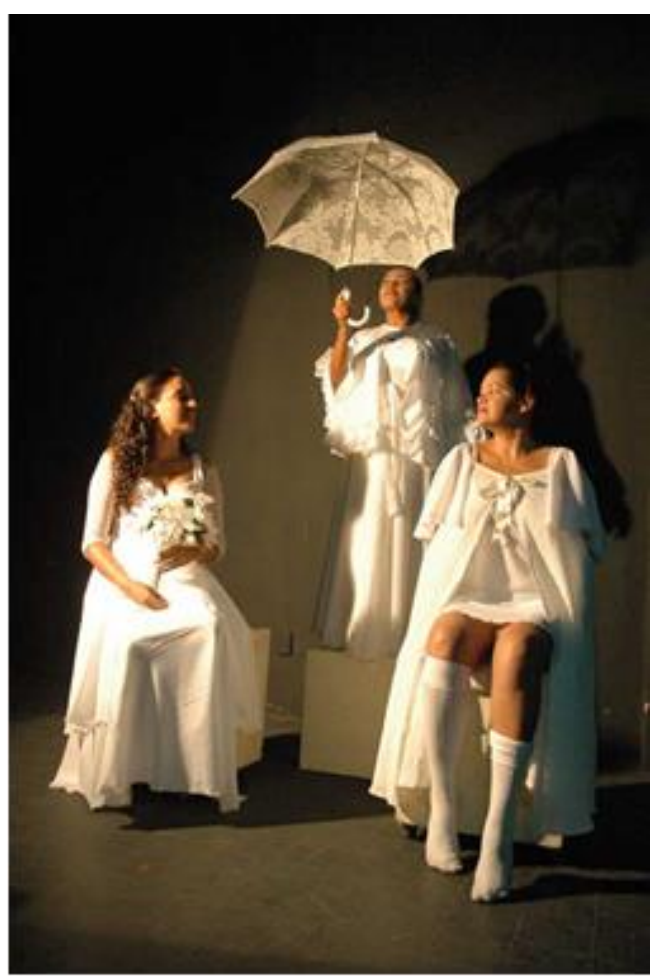

Imagem 1 - Espetáculo "A palavra é gesto". Fonte: http://www.grupoestandarte.com.br/online/galeria/fotos

$\mathrm{Na}$ narrativa de Albuquerque, a relação entre linguagens artísticas e a arte literária a conduz a escolha da Literatura de Cordel como prática de linguagem a ser apresentada às crianças. A preferência pela arte literária é decorrente das 
experiências da autora com esse conteúdo/linguagem desde a infância. Ela faz o relato de situações e contextos prazerosos de acesso ao repertório cultural da literatura, como leitora, ao mesmo tempo em que, como professora, organiza experiências educativas que propiciem às crianças o prazer do contato com os textos. No texto de Albuquerque, as práticas e atividades de linguagens são vivenciadas tanto pela professora como pelas crianças, pois fazem parte de um repertório estético e artístico da cidade em que estão inseridos com seres culturais (ALBUQUERQUE, 2007).

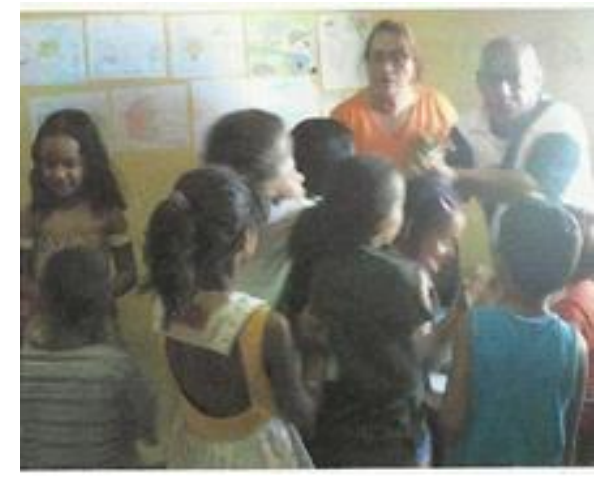

Imagem 02: A chegada do poeta.

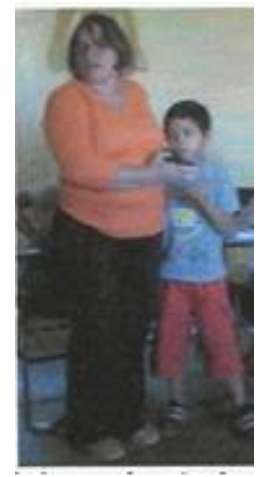

Imagem 03: Leitura de cordel.

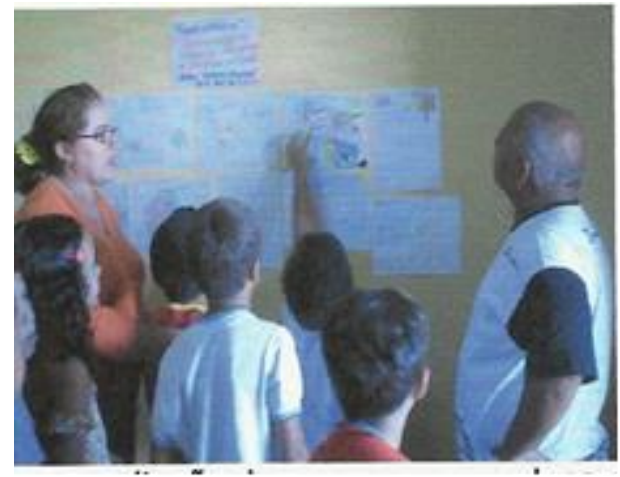

Imagem 04: Apresentação do projeto.

Fonte das imagens 02 a 04: Albuquerque, 2007, p. 45

O texto de Pinheiro (2007) traz o brinquedo cantado como experiência com linguagens artísticas na infância e o ensino de música e dança como uma vivência de escolarização. No entanto, o projeto desenvolvido com seus alunos tem como foco o processo criativo de Frans Krajcberg. A escolha do tema está relacionada ao projeto pedagógico da escola, mas a ênfase na temática da criatividade, arte e meio ambiente é uma opção dessa professora ao longo da escrita de seu memorial.

Sousa (2007) trata, entre outros assuntos, da articulação entre as experiências das crianças fora dos muros da escola e a prática docente. Salienta que o brincar é a prática corporal mais exercida pelas crianças. A autora traz relatos de sua infância, sobre brincadeiras e brinquedos e faz um levantamento das brincadeiras das crianças no bairro em que trabalha. Ela diversifica os seus estudos sobre práticas corporais quando apresenta às crianças a dança dos Caboclinhos do Rio Grande do Norte. A justificativa para tal escolha é a de favorecer o acesso das crianças ao rico acervo da cultura do RN. 


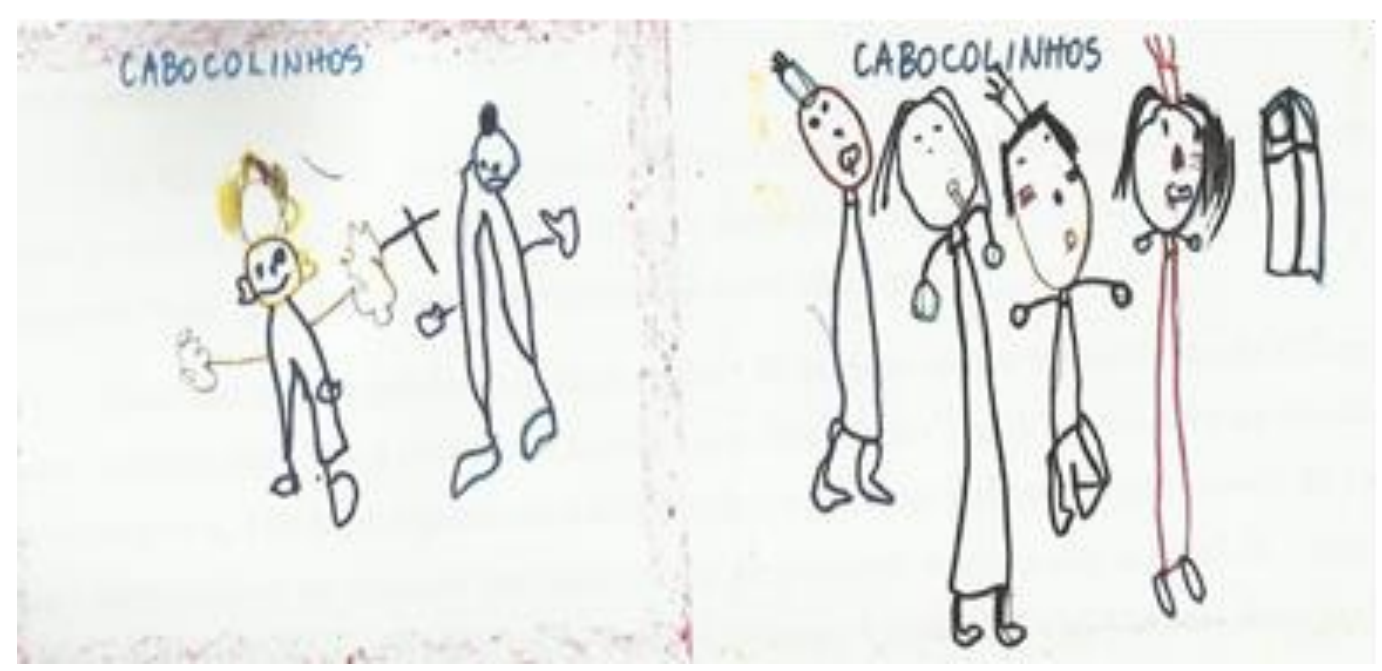

Imagens 05 e 06: Desenhos da dança dos Caboclinhos (SOUSA, 2007, p. 33)

Medeiros (2007) localiza na região de serras que rodeiam a cidade onde nasceu, cavernas com pinturas rupestres. A leitura que faz das imagens da sua ambiência de infância é levada para sala de aula e apresentada às crianças. Para contagiar as crianças com o tema das pinturas rupestres do $\mathrm{RN}$, o professor articula intencionalmente formas de expressão próximas às práticas de linguagens das crianças - contação de história, brincadeiras, desenhos e pinturas em suportes amplos. O conteúdo que o professor pretende tornar visível para as crianças está interligado às formas de expressão que ele articula para tornar as pinturas rupestres significativas para o grupo.

$\mathrm{Na}$ abordagem de suas infâncias os professores ressaltam encontros estésicos com a ambiência cultural e natural. As sensações são enfatizadas como forma primeira de conhecimento do entorno. Eles rememoram sons, gostos, texturas, cores e cheiros de forma contextualizada atribuindo sentidos ao espaço histórico e geográfico em que viveram essa fase de suas vidas. Nessa parte das narrativas, a cidade é objeto estético sobre os qual os professores exercem leituras. Ela thes apresenta elementos culturais que são retomados em suas práticas docentes.

A infância é narrada destacando sua positividade e, às vezes, de forma romantizada. Nas metamemórias de infância a ludicidade é apresentada como uma característica marcante da interação das crianças com os conteúdos culturais. Nas narrativas dos professores sobre suas experiências, a dimensão estética é aliada à dimensão lúdica do ser no mundo. Quando escrevem sobre a prática docente o lúdico, 
especialmente representado pelas brincadeiras e brinquedos, aparece como forma de mediar o acesso das crianças às linguagens artísticas.

Ainda tratando de mediação, constatamos que as formas de expressão dos professores são estratégias de ensino importantes para provocar o contágio das crianças pelas conteúdos/linguagens da arte.

As culturas da infância, culturas escolares, culturas das famílias e culturas da comunidade são tematizadas pelos professores com o objetivo de estabelecer o diálogo entre os diferentes repertórios estéticos e artísticos que permeiam tais instâncias sociais. Os critérios de escolha dos conteúdos/linguagens artísticas consideram o diálogo entre culturas e o interesse das crianças pelos temas. Desse modo, a relação entre experiência estética e cultura é fundamental para a articulação dos processos de ensino e aprendizagem.

A organização do conteúdo em projetos didáticos favoreceu a produção de experiências educativas em que as situações de aprendizagem foram vivenciadas de forma encadeada observando a continuidade entre elas.

\section{Conclusões}

Nesta pesquisa, a rememoração das experiências e a produção escrita das narrativas possibilitaram aos professores a articulação entre suas experiências estéticas e artísticas e as práticas docentes. $O$ ato de escrever intencionalmente sobre processos de formação exigiu dos autores dos memoriais a reflexão sobre os significados de sua atuação na educação da infância.

No que se refere ao movimento de construção da pesquisa, foi necessário articular saberes de áreas diversas - arte, educação, filosofia - para a construção de um referencial que permitisse a leitura dos memoriais de formação. Um referencial que considerasse o professor como sujeito de suas experiências estéticas, autor de práticas docentes e da escrita sobre suas práticas. Dessa forma, priorizou-se a premissa de que tudo está em relação. O indivíduo se constitui com outros, entre outros. Uma referência cultural é formada por inferência de várias outras. Uma palavra existe em sua relação com outras. Assim, o movimento relacional, que é marca 
registrada da vida vivida se constituiu, também, como caminho de produção de pesquisa.

As interfaces entre experiências estéticas, ensino e arte apontaram para a consideração de que as experiências estéticas dos professores foram produzidas em espaços formais e não formais de educação. Esses ambientes de interação não são excludentes e influenciam no que é proposto pelos professores nas escolas.

O desafio da escrita do memorial, como um dos momentos de reflexão sobre a prática, fez com que o professor, autor de sua escrita, retomasse as interfaces entre suas experiências estéticas e sua atuação docente ao propor situações de aprendizagem da arte. Nesse movimento ele se coloca, ao mesmo tempo, como sujeito que vivenciou e vivencia a experiência estética e como sujeito que propõe, organiza, ou desencadeia novas experiências para as crianças.

\section{Referências}

ALBUQUERQUE, Maria Margreth Freire. Lembranças de minhas leituras: o despertar prazeroso pela arte literária. (Memorial descritivo de Formação - Curso de Especialização em Ensino de Arte e Educação Física na Infância). 2007. Universidade Federal do Rio Grande do Norte, Mossoró, RN.

BARBOSA, Ana Mae. Tópicos utópicos. Belo Horizonte: C/ Arte, 1998.

BARBOSA, Ana Mae. A imagem no ensino de arte: anos 1980 e novos tempos. $7^{a}$ ed. rev. São Paulo: Perspectiva, 2009.

CHARLOT, Bernard. Da relação com o saber: elementos para uma teoria. Tradução Bruno Magne. Porto Alegre: Artmed, 2000.

DEWEY, John. Arte como experiência. Tradução de Vera Ribeiro. São Paulo: Martins Fontes, 2010.

GREIMAS, Algirdas. Julien. Da imperfeição. São Paulo: Hacker Editores, 2002.

LANDOWSKI, Eric. O olhar comprometido. Revista Galáxia, São Paulo, n 2, p. 19-56, 2001.

LANDOWSKI, Eric. Aquém ou além das estratégias, a presença contagiosa. Documentos de Estudo do Centro de Pesquisas Sociossemióticas, n. 3. São Paulo: Edições CPS, 2005.

MEDEIROS, Maurício José de. Memórias das imagens do tempo: (re) desenhando relatos de experiências exitosos. (Memorial descritivo de Formação - Curso de Especialização em Ensino de Arte e Educação Física na Infância). 2007. Universidade Federal do Rio Grande do Norte, Natal, RN.

MERLEAU-PONTY, Maurice. Maurice Merleau-Ponty: textos selecionados. Organização e Tradução de Marilena de Souza Chauí. São Paulo: Abril Cultural, 1980. (Os pensadores).

MERLEAU-PONTY, Maurice. Fenomenologia da percepção. Tradução de Carlos Alberto Ribeiro de Moura. São Paulo: Martins Fontes, 1999.

MERLEAU-PONTY, Maurice. O olho e o espírito. Tradução de Paulo Neves e Maria Ermantina Gomes. São Paulo: Cosac \& Naify, 2004.

PASSEGI, Maria da Conceição. Memoriais: injunção institucional e sedução autobiográfica. In: PASSEGI, Maria da Conceição; SOUZA, Elizeu Clementino (Orgs.). (Auto)Biografia: formação, territórios e saberes. Natal, RN: EDUFRN; São Paulo: Paulus, 2008. p. 103-131. 
PINHEIRO, Maria das Graças Bezerra. História vital. (Memorial descritivo de Formação - Curso de Especialização em Ensino de Arte e Educação Física na Infância). 2007. Universidade Federal do Rio Grande do Norte, Natal, RN.

PILLAR, Analice Dutra. (Org.). A educação do olhar no ensino de arte. Porto Alegre: Mediação, 1997.

PILLAR, Analice Dutra. A Educação do Olhar no Ensino de Arte. In: BARBOSA, Ana Mae Tavares Bastos (Org.). Inquietações e mudanças no ensino de arte. São Paulo: Cortez, 2002. p. 71-82.

PILLAR, Analice Dutra. Sincretismo em desenho animado. In: Educação \& Realidade. V. 30 n. 2 jul./dez. 2005. Porto Alegre: UFRGS. p. 123-142.

ROSSI, Maria Helena Wagner. Imagens que falam: leitura da arte na escola. Porto Alegre: Mediação, 2003.

SOUSA, Josefa Jeane Gomes. Entre o saber, o buscar e o fazer: trajetória e perspectiva de uma formação. (Memorial descritivo de Formação - Curso de Especialização em Ensino de Arte e Educação Física na Infância). 2007. Universidade Federal do Rio Grande do Norte, Natal, RN.

VITOR, Maria de Lourdes. Cenas da vida de uma educadora construída com: arte, teoria e movimentos. (Memorial descritivo de Formação - Curso de Especialização em Ensino de Arte e Educação Física na Infância). 2007. Universidade Federal do Rio Grande do Norte, Parnamirim, RN.

\section{Gilvânia Maurício Dias de Pontes}

Doutora em Educação pela UFRGS. Mestre em Educação pela UFRN. Professora do Núcleo de Educação da Infância, Colégio de Aplicação da UFRN. Atua na Educação Infantil e Formação de Professores.

E-mail: gilvaniapontes@hotmail.com

Currículo: http://lattes.cnpq.br/2536072255193237 